\title{
LA PRESCRIPCIÓN DE LAS ACCIONES REPARATORIAS CIVILES EMANADAS DE LOS CRÍMENES DE LESA HUMANIDAD
}

\author{
Mario Campos Poblete* \\ Universidad de Talca, Chile \\ mario_campos_p@hotmail.com
}

RESUMEN: La presente investigación tiene por objeto principal realizar un análisis de la aplicación que tiene la institución de la prescripción extintiva, respecto a las acciones reparatorias civiles derivadas de los crímenes de lesa humanidad. El estudio de esta temática obedece a que la jurisprudencia nacional se ha mostrado vacilante en torno a aceptar que la imprescriptibilidad de los crímenes contra la humanidad se hace extensiva tanto a la acción civil y penal que emanan de estos ilícitos internacionales.

Palabras clave: crimen de lesa humanidad, acción civil, imprescriptibilidad, Corte Penal Internacional.

\begin{abstract}
The following research has as main objective analyse the application of the institution of the liberative prescription, of the reparation actions with regards to the crimes against humanity. The subject of this research, obeys to the fact that national jurisprudence has been hesitant about accepting that imprescriptibility of the crimes against humanity is extended whether to the civil and criminal action, that comes from this international crimes.
\end{abstract}

Keywords: crime against humanity, civil action, imprescribility, International Criminal Court.

* Egresado de la carrera de Licenciatura en Ciencias Jurídicas y Sociales en la Universidad de Talca. Ayudante de las cátedras de Derecho Administrativo, Derecho del Estado y Jurisdicción Constitucional, y Memoria I. Investigador Asociado Centro de Estudios Ius Novum. 


\section{PLANTEAMIENTO DEL CONTENIDO DE LOS CRÍMENES CONTRA LA HUMANIDAD}

\subsection{ANTECEDENTES históricos EN LA ESFERA INTERNACIONAL}

Los inicios de las problemáticas de la persecución de la responsabilidad emanada de los crímenes de lesa humanidad los encontramos con posterioridad a la I Guerra Mundial, donde surgieron los primitivos intentos de establecer una jurisdicción penal internacional, paralelos a la incorporación de la responsabilidad penal de los individuos en el orden internacional. Más tarde, en el marco de la Sociedad de las Naciones, se aprobó la Convención para la represión del terrorismo, de 16 de noviembre de 1937, en la que se preveía la creación de una corte penal internacional, que, sin embargo, no llegó a entrar en vigor ${ }^{1}$. Asimismo, con los tribunales de Nuremberg y Tokio se comienza a gestar un Derecho Penal Internacional (DPI), mediante el cual se dota de operatividad el repudio a los crímenes contra la humanidad. Sin embargo, "el paso cardinal se produjo a raíz de la guerra en los Balcanes y en la región de África Central, en Ruanda y Burundi, durante los primeros ańos de la década de los 90. Estos conflictos condujeron a la creación de dos tribunales internacionales penales ad hoc, para juzgar las graves violaciones a los DD.HH. y al DIH producidas durante los mismos"2.

Todo ello, ha dado lugar al establecimiento de la Corte Penal Internacional (CPI), contenida en el Estatuto de Roma de 1998, que al 21 de julio de 2009 cuenta con 110 Estados partes. El Estado chileno depositó el instrumento de ratificación el día 29 de junio de $2009^{3}$.

\subsection{Antecedentes históricos en el Ámbito Regional y nacional}

En América Latina, en la década de los setenta y ochenta (Perú, Argentina y América Central, en el caso peruano incluso hasta los primeros años de los noventa), se cometieron violaciones masivas de DD.HH., donde Chile vivió un régimen autoritario que llevó a cabo su política represiva, conculcando los derechos de los contrarios al régimen. A raíz de eso es que "en 1975, la Comisión de DD.HH. de las Naciones Unidas creó un Grupo de Trabajo

1 Lirola Delgado, Isabel y Martín Martínez, Magdalena. La Corte Penal Internacional, Justicia versus Impunidad. -1a edición- Barcelona, España: Editorial Ariel S.A., 2001, p. 39.

2 Aguilar Cavallo, Gonzalo. "Crímenes internacionales y la imprescriptibilidad de la acción penal y civil: referencia al caso chileno”, en: Revista Ius et Praxis, ańo 14 n². Talca, Chile: Universidad de Talca, 2008, pp. 148-149.

3 Información disponible en el sitio virtual de la Corte Penal Internacional. <En línea $>$ [citado el 25 de junio de 2010] Disponible en la World Wide Web: <http://www.icc-cpi.int/Menus/ASP/states+parties/The+States+Parties+to+the+Rome+Sta tute.htm> 


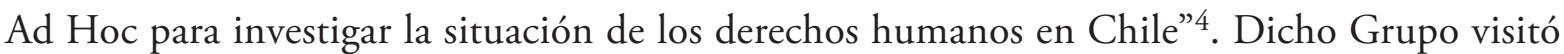
Chile solo en julio de 1978 y señaló que era preciso establecer una comisión independiente bajo la legislación chilena, para investigar el destino de las víctimas desaparecidas, juzgar a los responsables y otorgar la correspondiente reparación, pero "la propuesta fue rechazada por el gobierno chileno al afirmar que el poder judicial constituía la única autoridad competente en Chile para investigar los delitos penales y que por lo tanto los investigadores extranjeros

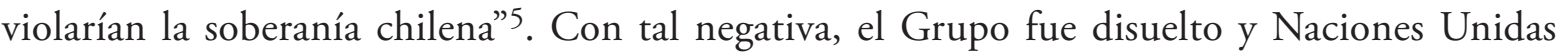
designó a un experto para que estudiara la cuestión de las personas desaparecidas en Chile, informe que entregó a la Asamblea General en 1979 y otro a la C. de DD.HH. en 1980, en ellos señaló que "si no se identifica y castiga a los responsables, podría ocurrir que hubiese quienes viesen las desapariciones como un método operativo aceptable para administrar la seguridad nacional en el futuro" 6 . El gobierno militar en el año 1978 había dictado el DL 2.191 de Amnistía para los responsables de los actos comprendidos entre los ańos 1973 y 1978, lo que impidió dilucidar el paradero de cientos de detenidos desaparecidos.

Con el retorno a la democracia se investigaron las desapariciones forzadas, dando lugar a que "en 1991 se [hiciera] público el informe de la Comisión para la Verdad y la Reconciliación en que se atribuye al Gobierno militar la muerte de más de dos mil personas así

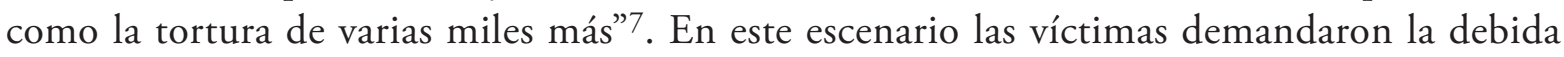
sanción penal para los culpables y la consiguiente reparación pecuniaria por parte del Estado. Se aprecia que los tribunales en esta materia han ido evolucionando, pues en un principio se aplicaba el DL de Amnistía, lo que cambió con la fuerte arremetida de los DD.HH., acogiéndose en sentencias principios de Derecho Internacional, convencional y consuetudinario.

\subsection{CONCEPTUALización DE LOS CRÍMENES DE LESA HUMANidAD}

El término "crimen contra la humanidad" ha sido utilizado como sinónimo de la expresión "crimen de lesa humanidad", así se colige al observar diversos textos doctrinarios y jurisprudencia, a nivel nacional e internacional ${ }^{8}$. Además, desde una perspectiva gramatical, la traducción al español del articulado del Estatuto de la CPI, se observan como sinónimos

4 Blanc Altemir, Antonio. La violación de los derechos humanos fundamentales como crimen internacional -1a edición- Barcelona, España: Bosch Casa Editorial S.A., 1990, p. 349.

5 Ibid.

$6 \quad$ Ibid., p. 350-351.

7 Ferrer Lloret, Jaume. Responsabilidad Internacional del Estado y Derechos Humanos -1a edición- Madrid, España: Editorial Tecnos S.A., 1998, pp. 83-84.

8 A modo ejemplar, ver: Benadava, Santiago, Derecho Internacional Público -8a edición- Santiago, Chile: LexisNexis, 2004, p. 227; y Quel López, Francisco Javier. Los tribunales Penales Internacionales Ad Hoc. En: Fernández de Casadevante Romani, Carlos (coordinador), Derecho Internacional de los Derechos Humanos -3a edición- Madrid, España: Editorial Dilex S.L., 2007. p. 432. 
ambas locuciones, dualidad que no se da en otros idiomas, por ejemplo, en el idioma francés se utiliza la expresión "crime contre l'humanité” y en inglés se usa la voz "crime against humanity". Para el desarrollo de este trabajo, ambos conceptos serán empleados de forma indistinta.

Conforme señala Gamboa Serazzi, existe "ausencia de una definición que sea aceptada por el Derecho Internacional de crímenes de lesa humanidad. No obstante ello, existen numerosos instrumentos internacionales que consagran actos constitutivos de este delito"', entre ellos tenemos el Estatuto del TMI de Nuremberg (artículo $6^{\circ 10}$ ), el Estatuto del TMI para el Lejano Oriente (artículo $5^{\circ}$ ), el TPI para la ex Yugoslavia (artículo $5^{\circ 11}$ ), el TPI para Ruanda (artículo $3^{\circ 12}$ ) y el art. 18 del Proyecto de Código de Crímenes contra la Paz y la Seguridad de la Humanidad de la CDI, de $1996^{13}$. Dichos cuerpos normativos solo enumeran comportamientos que se estiman crímenes contra la humanidad y ello obedece, en palabras de Quel López, a que se trata de un concepto "multívoco, pues de acuerdo a la expresión misma que engloba las conductas punibles, éstas únicamente se definen por referencia a los denominados actos inhumanos que chocan con la conciencia colectiva en la medida en que lesionan al ser humano de manera tal que trascienden al individuo que sufre el daño"14.

9 Gamboa Serazzi, Fernando y Fernández Undurraga, Macarena. Tratado de Derecho Internacional Público y Derecho de Integración-2a edición-Santiago, Chile: LexisNexis, 2008, p. 415.

10 "Artículo 6 ${ }^{\circ}$ El Tribunal establecido por el Acuerdo aludido en el Artículo 1 del presente para el enjuiciamiento y condena de los principales criminales de guerra del Eje Europeo estará facultado para juzgar y condenar a aquellas personas que, actuando en defensa de los intereses de los países del Eje Europeo, cometieron los delitos que constan a continuación, ya fuera individualmente o como miembros de organizaciones: Cualesquiera de los actos que constan a continuación son crímenes que recaen bajo la competencia del Tribunal respecto de los cuales habrá responsabilidad personal: C) Crímenes contra la humanidad: A saber, el asesinato, la exterminación, esclavización, deportación y otros actos inhumanos cometidos contra población civil antes de la guerra o durante la misma; la persecución por motivos políticos, raciales o religiosos en ejecución de aquellos crímenes que sean competencia del Tribunal o en relación con los mismos, constituyan o no una vulneración de la legislación interna de país donde se perpetraron". <En línea> p. 3 [citado el 25 de junio de 2010] Disponible en la World Wide Web: <http://www.cruzroja.es/dih/pdf/estatuto_del_tribunal_militar_internacional_de_nuremberg.pdf>

11 Artículo 5. Crímenes contra la humanidad. El Tribunal Internacional tendrá competencia para enjuiciar a los presuntos responsables de los crímenes que se señalan a continuación, cuando hayan sido cometidos contra la población civil durante un conflicto armado, interno o internacional: a) Asesinato; b) Exterminio; c) Esclavitud; d) Deportación; e) Encarcelamiento; f) Tortura; g) Violación; h) Persecución por motivos políticos, raciales o religiosos; e i) Otros actos inhumanos. Valencia Villa, Alejandro (compilador y editor general), Compilación de Derecho Penal Internacional, El Estatuto de Roma y otros instrumentos de la Corte Penal Internacional. -1a edición- Bogotá, Colombia: Oficina en Colombia del Alto Comisionado de las Naciones Unidas para los Derechos Humanos, 2003, p. 285.

12 Artículo 3. Crímenes de lesa humanidad: El Tribunal Internacional para Rwanda tendrá competencia para enjuiciar a los presuntos responsables de los crímenes que se señalan a continuación, cuando hayan sido cometidos como parte de un ataque generalizado o sistemático contra la población civil por razones de nacionalidad o por razones políticas, étnicas, raciales o religiosas: a) Homicidio intencional; b) Exterminio; c) Esclavitud; d) Deportación; e) Encarcelación; f) Tortura; g) Violación; h) Persecución por motivos políticos, raciales o religiosas: e i) Otros actos inhumanos.

Ibid., p. 298.

13 Lirola Delgado, Isabel y Martín Martínez, Magdalena. op. cit. (n. 1), p. 123; y Quel López, Francisco Javier. op. cit. (n. 8), p. 434.

14 Ibid. 
Ante la carencia de uniformidad en el concepto, surgen dos cuestiones a solucionar en el plano técnico, en primer término, el problema de determinar el sentido de la noción y, por otra parte, la pregunta de quién es competente para dar una definición que, si la hubiere, prevalecerá a los demás Estados ${ }^{15}$. Empero, una visión actual de estos ilícitos la entrega el art. 7.1 del Estatuto de la CPI que no solo enumera las conductas que lo configuran, sino que también las define.

Pérez-León Acevedo enuncia que "de acuerdo al Estatuto de la CPI, se entenderá que, entre otros, actos como el asesinato, exterminio, tortura o desaparición forzada constituyen crímenes de lesa humanidad cuando se cometan como parte de un ataque generalizado o sistemático contra una población civil y con conocimiento de dicho ataque"16.

Por su parte, Jiménez García aprecia que "la amplitud de este tipo criminal que se presenta como autónomo de la existencia o no de un conflicto armado interno o internacional, ha obligado a que a continuación el artículo 7.2 concrete el alcance de los términos empleados en su párrafo primero"17. A su vez, en el actual fraseo se desarrollan con una mayor precisión, tanto los actos que pueden calificar dentro de esta categoría, así como los respectivos elementos contextuales y específicos, materiales y mentales que lo caracterizan $^{18}$.

Por último, la doctrina, siguiendo a Robinson, reconoce que los elementos definitorios de este concepto hacen referencia a los siguientes aspectos: a.- La ausencia del requisito de la conexión con un conflicto armado; b.- El carácter generalizado o sistemático del ata-

15 “...deux questions apparaissent sur le plan technique... il se pose d'une part le problème de la détermination du sens de la notion et d'autre part la question de savoir qui est compétent pour donner une définition qui, le cas échéant, s'imposera à des souverainetés", en Roulot, Jean-François, Le crime contre l'humanité. -1a edición- París, Francia: Editorial L'Harmattan, 2002, p. 23.

16 El autor agrega que "según el Estatuto de la CPI, siempre que se cumplan los elementos citados, los actos que pueden calificar como crímenes de lesa humanidad son: a) Asesinato; b) Exterminio; c) Esclavitud; d) Deportación o traslado forzoso de población; e) Encarcelación u otra privación grave de la libertad física en violación de normas fundamentales de derecho internacional; f) Tortura; g) Violación, esclavitud sexual, prostitución forzada, embarazo forzado, esterilización forzada o cualquier otra forma de violencia sexual de gravedad comparable; h) Persecución de un grupo o colectividad con identidad propia fundada en motivos políticos, raciales, nacionales, étnicos, culturales, religiosos, de género definido en el párrafo 3, u otros motivos universalmente reconocidos como inaceptables con arreglo al derecho internacional, en conexión con cualquier acto mencionado en el presente párrafo o con cualquier crimen de la competencia de la Corte; i) Desaparición forzada de personas; j) El crimen de apartheid; k) Otros actos inhumanos de carácter similar que causen intencionalmente grandes sufrimientos o atenten gravemente contra la integridad física o la salud mental o física”. PÉrezLeón Acevedo, Juan Pablo. "Las violaciones graves de los derechos humanos como crímenes de lesa humanidad", en Revista del Observatorio Regional sobre Corte Penal Internacional y Derecho Penal Internacional. <En línea> $\mathrm{N}^{\circ} 2$, mayo 2008, p. 183 [citado el 25 julio 2010] Disponible en la World Wide Web <http://www.observatoriodpi.org/_data/spda/ contenido/20080506125954_.pdf>

17 Jiménez García, Francisco. La Corte Penal Internacional. En: Fernández de Casadevante Romani, Carlos (coordinador), op. cit. (n. 8), p. 464.

18 Véase los "Elementos de los Crímenes del Estatuto de la Corte Penal Internacional", Valencia Villa, Alejandro (compilador y editor general), op. cit. (n. 11), pp. 105-115. 
que contra una población civil; c.- La ausencia del requisito de la existencia de motivos discriminatorios; y d.- El elemento subjetivo del conocimiento de dicho ataque ${ }^{19}$.

\subsection{RegulaCión EN EL ORDENAMiento JURÍdico NACiONAL}

Las violaciones a los DD.HH. cometidas durante el régimen autoritario en Chile, conforme a la doctrina y jurisprudencia, son constitutivas de crímenes de lesa humanidad, por lo cual se señala son imprescriptibles, situación que se ve reforzada con la dictación de la Ley n ${ }^{\circ} 20.357$ y la ratificación del Estatuto de la CPI. La mencionada ley, publicada en el D.O. el 18 de julio de 2009, tipifica los crímenes de lesa humanidad, genocidio, y crímenes y delitos de guerra, regulando los primeros con mayor precisión que el Estatuto de la CPI, pues en el art. $1^{\circ}$ se reitera solo una parte del art. $7^{\circ}$ del Estatuto pues no se exige que exista "conocimiento de dicho ataque", requisito que según los Elementos de los Crímenes "no debe interpretarse en el sentido que requiera prueba que el autor tuviera conocimientos de todas las características del ataque ni de los detalles precisos del plan o la política del Estado o la organización, dicha cláusula de intencionalidad existe si el autor tenía la intención de cometer un ataque de esa índole" ${ }^{20}$. Es menester decir que la regulación nacional tuvo en consideración diversos textos internacionales ${ }^{21}$, ello se evidencia en la historia de la tramitación de dicha ley.

Asimismo, el art. $2^{\circ}$ de la Ley define "ataque generalizado" y "ataque sistemático" de la siguiente manera: $1^{\circ}$. Por "ataque generalizado", un mismo acto o varios actos simultáneos o inmediatamente sucesivos, que afectan o son dirigidos a un número considerable de personas; y $2^{\circ}$. Por "ataque sistemático", una serie de actos sucesivos que se extienden por un cierto período de tiempo y que afectan o son dirigidos a un número considerable de personas. Conceptos que son una novedad frente al tratamiento que le otorga el art. 7.2 letra a) del Estatuto, pues este no distingue cuando será "generalizado" y cuando será "sistemático". Luego, entre los arts. $3^{\circ}$ y 10 se desarrollan las conductas que consagra el Estatuto de Roma como crímenes de lesa humanidad, describiendo ciertas situaciones, a las cuales asigna penas conforme a su gravedad, finalidad y efectos en las víctimas.

19 Lirola Delgado, Isabel y Martín Martínez, Magdalena. op. cit. (n. 1), pp. 119-120.

20 Valencia Villa, Alejandro (compilador y editor general). op. cit. (n. 11), p. 106.

21 Para mayor detalle, ver Historia de la Ley 20.357. <En línea> Disponible en la World Wide Web: <http://www.bcn.cl/ histley/lfs/hdl-20357/HL20357.pdf>, en especial página número 25 que señala los textos internacionales que se tuvieron en consideración para elaborar la normativa relativa a los crímenes de lesa humanidad. 
El proceso de ratificación de la CPI trajo consigo la inserción de la disposición vigesimocuarta transitoria en la $\mathrm{CPR}^{22}$, reconociendo la jurisdicción de la CPI y consagrando el principio de complementariedad ${ }^{23}$. Estas modificaciones fueron necesarias pues existía el pronunciamiento del TC, del año 2002, requerimiento formulado con el objeto que se declarase la inconstitucionalidad del Estatuto de Roma de acuerdo al artículo $82 \mathrm{n}^{\circ} 2$ de la CPR. El pronunciamiento del TC consta en la sentencia Rol n 346, de 8 de abril de 2002, oportunidad en la cual el órgano requerido consideró que las disposiciones del Estatuto atentaban contra la soberanía nacional ${ }^{24}$, principio consagrado en el art. $5^{\circ}$ de la CPR, resolviendo que "para su aprobación por el Congreso Nacional y su posterior ratificación por el Presidente de la República se requiere de reforma constitucional previa”. En cambio, cierto sector de la doctrina nacional sostiene que el Estatuto es un tratado de DD.HH., por lo cual ingresa de forma directa a la Constitución material en virtud del ya esgrimido art. $5^{\circ}$ de la CPR, precepto que reconoce como limitaciones "el respeto a los derechos esenciales que emanan de la naturaleza”. En nuestra opinión, el Estatuto de la CPI en estricto rigor es un Tratado de procedimientos, de carácter adjetivo, pues no reconoce DD.HH., sino que instaura una serie de instituciones propias del procedimiento que se han gestado con el tiempo.

22 Esta modificación se realizó a través de la Ley n ${ }^{\circ} 20.352$, publicada en el D.O. el 30 de mayo de 2009, que en su artículo único señala que: "El Estado de Chile podrá reconocer la jurisdicción de la Corte Penal Internacional en los términos previstos en el tratado aprobado en la ciudad de Roma, el 17 de julio de 1998, por la Conferencia Diplomática de Plenipotenciarios de las Naciones Unidas sobre el establecimiento de dicha Corte. / Al efectuar ese reconocimiento, Chile reafirma su facultad preferente para ejercer su jurisdicción penal en relación con la jurisdicción de la Corte. Esta última será subsidiaria de la primera, en los términos previstos en el Estatuto de Roma que creó la Corte Penal Internacional. I La cooperación y asistencia entre las autoridades nacionales competentes y la Corte Penal Internacional, así como los procedimientos judiciales y administrativos a que hubiere lugar, se sujetarán a lo que disponga la ley chilena. / La jurisdicción de la Corte Penal Internacional, en los términos previstos en su Estatuto, solo se podrá ejercer respecto de los crímenes de su competencia cuyo principio de ejecución sea posterior a la entrada en vigor en Chile del Estatuto de Roma”.

23 "El Estatuto de Roma se limita a enunciar tal principio en el Preámbulo y en el referido artículo 1 sin definir directamente su alcance y operatividad. Como ha indicado la profesora C. Escobar Hernández, el principio de complementariedad implica que la Corte solo podrá ejercer su competencia cuando las jurisdicciones nacionales no puedan o no quieran enjuiciar los mismo hechos, o cuando el enjuiciamiento ya realizado suponga una sustracción del individuo a la acción de la justicia, se traduzca en una impunidad de facto o se realice en contra de los intereses de la justicia definidos en el Estatuto, o se produzca en un proceso que no respete las reglas mínimas del juicio justo tal como se define en los textos internacionales de protección de los derechos humanos". Jiménez García, Francisco, La Corte Penal Internacional. En: Fernández de Casadevante Romani, Carlos (coordinador), op. cit. (n. 8), p. 457.

24 En esta línea se enmarcan los considerandos $31^{\circ}, 42^{\circ}, 44^{\circ}, 45^{\circ}, 46^{\circ}, 51^{\circ}, 57^{\circ}, 58^{\circ}$ que señala de forma que "para que la Corte Penal Internacional sea un tribunal establecido para juzgar delitos cometidos en Chile, debe incorporarse al sistema interno mediante una adecuación constitucional”, $62^{\circ}, 72^{\circ}, 74^{\circ}$ que también hace alusión a la necesidad de una reforma constitucional, $81^{\circ}$ y $93^{\circ}$, entre otros [citado el 29 de junio de 2010] Disponible en World Wide Web: <http://www.tribunalconstitucional.cl/index.php/sentencias/download/pdf/274> 


\section{CONCEPTUALIZACIÓN DE VÍCTIMA}

\subsection{Planteamiento del problema}

En la doctrina penal se plantea "que la víctima ha sido la gran ausente en el proceso penal de todos los tiempos" 25 , pues el ordenamiento jurídico en general está estructurado en base al delincuente y al poder punitivo del Estado, donde al primero se le asegura un debido proceso, garantía que limita y regula el actuar del segundo.

\subsection{Regulación de VÍCtima EN EL DERECHO INTERNo}

El art. 108 inc. $1^{\circ}$ del Código Procesal Penal chileno señala "se considera víctima al ofendido por el delito", de lo cual Carocca concluye que es "aquella persona que sufre las consecuencias perniciosas del acto ilícito que se atribuye al imputado"26. Horvitz y López agregan que se trata del "titular del bien jurídico afectado por el delito, sea persona natural o jurídica. No es víctima el sujeto pasivo de la acción si no es, al mismo tiempo, titular del bien jurídico lesionado y protegido por el derecho penal"27, opinión, que señalan, no es la compartida por la Fiscalía Nacional del Ministerio Público ${ }^{28}$. El art. 108 agrega que "en los delitos cuya consecuencia fuere la muerte del ofendido y en los casos en que éste no pudiere ejercer los derechos que en este Código se le otorgan, se considerará víctima: a) al cónyuge y a los hijos; b) a los ascendientes; c) al conviviente; d) a los hermanos, y e) al adoptado o adoptante", en ese orden de prelación. El precepto trascrito se debe distinguir del "concepto de víctima que da origen a la responsabilidad civil, que está en la base de la acción civil que puede deducirse dentro del procedimiento penal, siendo ésta la que ha sufrido el daño que el responsable está obligado a reparar mediante la indemnización de perjuicios" 29 . En términos generales, se puede perseguir en sede penal la responsabilidad civil, pues, como señala Garrido Montt, "de la comisión de un hecho delictivo se desprende una doble responsabilidad. Una frente a la sociedad representada por el Estado, que puede traer aparejada una pena o una medida de seguridad, y otra frente a aquellos que sufrieron algún tipo de per-

25 Parma, Carlos, Víctimas. Estado de situación en el proceso penal argentino, en la obra colectiva Victimología y Victimodogmática. Una aproximación al estudio de la Victima en el Derecho penal, Coordinador: Luis Miguel Reyna Alfaro. -1a edición- Lima, Perú: ARA Editores E.I.R.L., 2003, p. 642.

Carocca Pérez, Alex. Manual el nuevo sistema procesal penal. -3a edición- Santiago, Chile: LexisNexis, 2005, p. 78.

27 Horvitz Lennon, María Inés y López Masle, Julián. Derecho procesal penal chileno. -1a edición- Santiago, Chile: Editorial Jurídica de Chile, 2007, p. 298.

28 Ver instructivo $n^{\circ} 11$ de la Fiscalía Nacional del Ministerio Público, en Oficio $n^{\circ} 143$, de 12 de octubre de 2000, sobre atención y protección a las víctimas en el nuevo Código Procesal Penal, el cual expresa que "ofendido por el delito es el sujeto pasivo del delito, es decir, el titular de los bienes jurídicos que se ven afectados por el delito. También es ofendido por el delito el sujeto pasivo de la acción, esto es, el que sufre la acción delictiva, aunque no sea titular del bien jurídico afectado", disponible en la sección "instructivos" de http://www.ministeriopublico.cl/, consultado el día 30 de junio de 2010.

Horvitz Lennon, María Inés y López MasLe, Julián, op. cit. (n. 27), p. 300. 
juicio como consecuencia del delito, que puede obligar a la reparación del daño causado"30. Agrega el autor, siguiendo a Fernández Carrasquilla, que "la responsabilidad penal es una consecuencia natural de todo delito, en tanto que la responsabilidad civil no siempre lo es, porque solo en determinadas hipótesis un delito da origen a una responsabilidad de esta naturaleza. Así sucede cuando siendo el hecho un delito penal, además lesiona intereses particulares de la víctima ${ }^{31}$ o de terceros, lesión que puede ser material o moral"32.

\subsection{REgulación DE VÍCTIMA EN EL DERECHO COMPARAdo}

La doctrina penal comparada señala que "la palabra víctima se refiere a la persona que sufre o es lesionada en su cuerpo o en sus bienes por otra" ${ }^{33}$, a lo que se debe sumar que en la nueva cosmovisión dogmática, las víctimas no equivalen al sujeto pasivo del delito.

Según la ONU: "se entenderá por víctimas las personas que, individual o colectivamente, hayan sufrido daños, inclusive lesiones físicas o mentales, sufrimiento emocional, pérdida financiera o menoscabo sustancial de los derechos fundamentales, como consecuencia de acciones u omisiones que violen la legislación penal vigente en los Estados Miembros, incluida la que proscribe el abuso del poder". También, "se incluye además, en su caso, a los familiares o personas a cargo que tengan relación inmediata con la víctima directa y a las personas que hayan sufrido daños al intervenir para asistir a la víctima en peligro o para prevenir la victimización" 34 . Asimismo, la Resolución ONU n 60/147 aprobada por la Asamblea General el 16 de diciembre de 2005, en el punto V, numerales 8 y 9, expresa lo siguiente: "8. A los efectos del presente documento, se entenderá por víctima a toda persona que haya sufrido daños, individual o colectivamente, incluidas lesiones físicas o mentales, sufrimiento emocional, pérdidas económicas o menoscabo sustancial de sus derechos fundamentales, como consecuencia de acciones u omisiones que constituyan una violación manifiesta de las normas internacionales de derechos humanos o una violación grave del derecho internacional humanitario. Cuando corresponda, y en conformidad con el derecho interno, el término "víctima" también comprenderá a la familia inmediata o las personas a cargo de la víctima directa y a las personas que hayan sufrido daños al intervenir para prestar asistencia a víctimas en peligro o para impedir la victimización. / 9. Una persona será considerada víctima con independencia de si el autor de la violación ha sido identificado,

30 Garrido Montt, Mario, Derecho Penal. -1a edición- Santiago, Chile: Editorial Jurídica de Chile, 1997, p. 385.

31 En el mismo sentido, Cury Urzúa, Enrique, Derecho Penal. Parte General. -8a edición ampliada- Santiago, Chile: Ediciones Universidad Católica de Chile, p. 807; Eтcheberry, Alfredo, Derecho Penal. Parte General, Tomo II. -3a edición revisada y actualizada- Santiago, Chile: Editorial Jurídica de Chile. 1998, pp. 235 y ss.

32 Garrido Montt, Mario. op. cit. (n. 30), p. 300.

33 Parma, Carlos. op. cit. (n. 25), p. 641.

34 Citado por Beristain, Antonio, Proceso penal y victimas: Pasado, presente y futuro,; y en una forma extractada citado por PARMa, Carlos. op. cit. (n. 33), ambos en la obra colectiva Victimología y Victimodogmática. Una aproximación al estudio de la Victima en el Derecho penal, op. cit. (n. 25), p. 675 y p. 641, respectivamente. 
aprehendido, juzgado o condenado y de la relación familiar que pueda existir entre el autor y la víctima” 35 . Se coligen 3 categorías: “-las víctimas individuales o colectivas, -las víctimas indirectas, y -las víctimas sin autor conocido o identificado”36, grupos que pueden presentarse conjuntamente ante un ilícito.

Desde una perspectiva victimológica se distingue entre víctima y perjudicados, siendo la víctima "el titular del bien jurídico penalmente protegido que ha sido dañado o puesto en peligro, y los perjudicados, aquellos otros sujetos que se ven directamente afectados por el delito, pero que no son titulares del bien jurídico lesionado o puesto en peligro" 37 .

Por su parte, las Reglas de Procedimiento y Prueba, de la CPI, regla ${ }^{\circ}$ 85, señalan: “a) Por "víctimas" se entenderá las personas naturales que hayan sufrido un daño como consecuencia de la comisión de algún crimen de la competencia de la Corte; b) Por víctimas se podrá entender también las organizaciones o instituciones que hayan sufrido daños directos a alguno de sus bienes que esté dedicado a la religión, la instrucción, las artes, las ciencias o la beneficencia y a sus monumentos históricos, hospitales y otros lugares y objetos que tengan fines humanitarios" 38 . Se consagra "la noción de víctima persona moral, en razón de un perjuicio amplio, calificado de "perjuicio humanitario". Esta concepción amplia de la noción de víctima es evidentemente original. Pero ella se aplica por la naturaleza misma de las violaciones específicas que el DPI está destinado a sancionar"39.

Por último, el art. 75 del Estatuto de Roma expresa que "la Corte tiene el poder de ordenar el pago de la reparación apropiada a las víctimas por parte de la persona condena$\mathrm{da}^{40}$

35 "Principios y directrices básicos sobre el derecho de las víctimas de violaciones manifiestas de las normas internacionales de derechos humanos y de violaciones graves del derecho internacional humanitario a interponer recursos y obtener reparaciones". <En línea> [citado el 30 de junio de 2010] Disponible en la World Wide Web: <http://www2.ohchr.org/ spanish/law/reparacione s.htm>

36 "-les victimes individuelles ou collectives, -les victimes indirectes, et -les victimes sans auteur connu ou identifié (violations massives: cf. Viols collectifs, épuration ethnique)", OтTEnHof, Reynald, "Les victimes de la criminalité dans un monde globalisé”. <En línea> ReAIDP/e-RIAPL, 2008, [citado el 30 de junio de 2010] Disponible en la World Wide Web: <http://www.penal.org/pdf/Guadalajara-Ottenhof.pdf>

37 Queralt Jiménez, Joan, Victimas y garantías: Algunos cabos sueltos a propósito del proyecto alternativo de reparación, en la obra colectiva Victimología y Victimodogmática. Una aproximación al estudio de la Victima en el Derecho penal. op. cit. (n. 25), p. 213-214.

38 Reglas de Procedimiento y Prueba, instrumento para la aplicación del Estatuto de la Corte Penal Internacional. <En línea> [citado el 02 de julio de 2010] Disponible en la World Wide Web: http://www.icc-cpi.int/NR/rdonlyres/F1E0AC1C-A3F3-4A3C-B9A7-B3E8B115E886/140167/Rules_of_procedure_and_Evidence_Spanish.pdf

39 "la notion de victime personne morale, à raison d'un préjudice très large, qualifié de "préjudice humanitaire". Cette conception large de la notion de victime est évidentement originale. Mais elle s'explique par la nature même des violations spécifiques que le DPI est amené à sanctionner”, Oтtenhof, Reynald. op. cit. (n. 36).

40 "la Cour a le pouvoir d'ordonner le paiement de la réparation appropriée aux victimes par la personne condamnée", Bassiouni, M. Cherif, Introduction au Droit Pénal International. Bruxelles, Belgique: Ed. Bruylant, 2002 , p. 277. 


\section{PRESCRIPCIÓN EXTINTIVA RESPECTO A LA ACCIÓN CIVIL DERIVADA DE CRÍMENES CONTRA LA HUMANIDAD}

\subsection{EXPOSICIÓN DEL PROBLEMA}

En Chile, frente a las demandas de las víctimas de violaciones a los DD.HH., cometidas durante el gobierno militar, se ha manifestado por la jurisprudencia que en el ámbito civil no pueden prosperar, puesto que ha operado la prescripción extintiva ${ }^{41}$. La doctrina nacional no ha sido muy generosa en este punto, aunque existen tratadistas que adoptan la posición de la imprescriptibilidad de la acción civil, se observa la carencia de fundamentos que la sostengan.

\subsection{Cuestiones PRELIMinares}

El Código Civil (CC) regula esta materia en lo que respecta a la responsabilidad extracontractual, siendo en la mayoría de los casos plenamente aplicable la prescripción, pues es patrimonial y, al estar establecida en beneficio del afectado, se entiende que es a su vez renunciable. Troncoso Larronde señala que "la regla general es que las acciones sean prescriptibles, no siendo necesario para este efecto que el legislador indique expresamente su prescripción. Por el contrario se requiere de una disposición expresa que establezca que una acción es imprescriptible" ${ }^{2}$. Ello es aplicable a las relaciones entre particulares, o de estos con el Estado en el plano doméstico, pues el CC no fue elaborado para regir la responsabilidad internacional del Estado que se origina con los crímenes de lesa humanidad.

\subsection{Argumentos de la doctrina IUS PUblicista naCiOnal E Internacional}

Aguilar Cavallo propone 6 niveles de argumentación; a saber:

\subsubsection{Principio de Derecho Internacional Convencional ${ }^{43}$}

El art. 29 del Estatuto de la CPI señala que "los crímenes de la competencia de la Corte no prescribirán”, observa el autor que no se distingue entre la acción civil o penal, siendo ambas imprescriptibles. Se critica que dicho cuerpo normativo es de carácter espe-

41 En cuanto a acoger la imprescriptibilidad de la acción civil ver sentencias de la Sala Penal de la Excma. Corte Suprema, Rol 6308-2007, de 8 de septiembre de 2008 (Vergara Vargas); Rol n 4662-2007, de 25 de septiembre de 2008 (Episodio Liquińe); Rol n 4723-2007, de 15 de octubre de 2008 (Episodio San Javier); Rol n 6212-2007, de 29 de octubre de 2008 (Lazo Lazo); Rol n 3907-2007, de 21 de enero de 2009 (Tormen), y un pronunciamiento de la Sala Civil, la sentencia Rol 2080-2008, de 8 de abril de 2010 (Ortega Fuentes). Los fallos mencionados responden a una alteración en la composición de la sala.

42 Troncoso Larronde, Hernán, De las obligaciones. -4a edición-Santiago, Chile: LexisNexis, 2006, p. 304.

43 Aguilar Cavallo, Gonzalo. op. cit. (n. 2), p. 178. 
cial, establece una CPI, siendo su aplicación en la esfera del DPI. Lo anterior, invita a revisar la génesis de la CPI, pues es ineludible que esta encuentra sus antecedentes en los hechos posteriores a la II Guerra Mundial. Los antecedentes a considerar son los TMI y ad hoc, cuyos textos reguladores no contemplan distinción entre la acción penal y civil. Roulot expresa que "el Acuerdo de Londres, no aborda el problema de la prescripción. Sin embargo, en referencia a la intención de los Estados firmantes del Acuerdo, la prescripción de los crímenes nazis es inconcebible tácitamente dentro de las medidas, donde a lo menos dos de los cuatro signatarios no la conocen" ${ }^{44}$. Esta normativa fue reproducida en los tribunales posteriores, en los cuales no se introdujo modificación en este aspecto. De acuerdo a esto se puede sostener que el Estatuto de la CPI, más allá de ser creado para el ámbito penal, también es aplicable en la esfera civil, pues los fundadores de sus bases (TMI Nuremberg) no consideraron la prescripción de forma expresa.

Aguilar Cavallo cita el art. 75 del Estatuto que trata la reparación a las víctimas, norma que conecta con la imprescriptibilidad de la acción civil. Se oponen Lirola Delgado y Martín Martínez, pues "la acción civil de reparación es independiente de la acción penal, por lo que su resolución no necesariamente corresponderá a la Corte" 45 .

\subsubsection{El falso argumento de la seguridad jurídica 46}

Aguilar Cavallo se pregunta si la seguridad y certeza jurídica, fundamentos de la prescripción, son para las víctimas y sus familiares o para los victimarios. Ello lleva a revisar si la prescripción es una institución absoluta en el ámbito de los ordenamientos jurídicos, a lo cual debemos esgrimir que "la prescripción no es una institución universal. Existen sistemas jurídicos, como por ejemplo los anglosajones, que no la conocen o al menos no le dan un carácter general” ${ }^{47}$. En esta línea, debemos entender que los crímenes contra la humanidad se enmarcan en el DIDH, que tiene por eje central la dignidad de la persona humana, donde el bien jurídico protegido está en un plano superior. Zaffaroni sostiene que "si la prescripción de estos crímenes no presentase características diferenciales de la prescripción de los restantes, la inviabilidad de la prescripción de las acciones que emergen de ellos debería investigarse en otro campo. Adelantamos la tesis de que ello es así, aunque la remisión a otro campo no carece de significación para el propio ámbito de los fundamentos de la prescripción”48. Al campo a que se refiere son las disposiciones del DPI, DIDH y el DIH.

\footnotetext{
44 ...n'aborde pas le problème de la prescription. Toutefois, en faisant référence à l'intention des Etats signataires de l'Accord, la prescription des crimes nazis est inconcevable tacitement dans la mesure où aun moins deux des quatre signataires ne la connaissent pas, en Roulot, Jean-François. op. cit. (n. 15), p. 395.

47 La prescription n'est pas une institution universelle. Il y a des systèmes juridiques, comme par exemple les droits anglosaxons, qui ne la connaissent pas ou du moins qui ne lui donnent pas un caractère général, en Roulot, Jean-Francois $o p$. cit. (n. 15), p. 395.

48 Zaffaroni, Eugenio Raúl. En torno de la cuestión penal. Montevideo-Buenos Aires: Editorial IB de F, 2005, p. 256.
} 


\subsubsection{Principio de coherencia ${ }^{49}$}

Si de un mismo hecho nacen ciertas acciones, darles un tratamiento distinto no guarda coherencia, por lo tanto, si de los crímenes contra la humanidad derivan acciones, civil y penal, ambas deben tener la misma suerte, es decir, se excepcionan de la prescripción extintiva. Este fundamento es rebatido por quienes señalan que desde la época de la codificación ambas acciones han sido reguladas de forma distinta, y están establecidas con objetivos diferentes. La acción penal lleva a cabo el juicio de reproche desde la perspectiva de la culpabilidad, busca la paz social y, por otro lado, la acción civil es la proyectada a establecer la responsabilidad del infractor y recibir la reparación del daño, que será para la satisfacción del ofendido. Sin embargo, desde la óptica de los crímenes internacionales se les debe dar un trato igualitario, debido a que los bienes jurídicos protegidos van más allá de la paz de una sociedad y de la propiedad de un ciudadano, se ampara la dignidad de la humanidad completa. En este orden de ideas, Guzmán Dalbora señala que "si estos delitos son comunes, con una acción penal prescriptible, pues es lógico que prescriba también la acción civil. Éste es hasta la fecha el pensamiento dominante entre los jueces -aunque solo relativamente a la última, no la primera-. Pero si se los considera en serio como crímenes internacionales, cae entonces por su base la pretensión del fisco de Chile en orden a estar exento del deber de pagar" 50 .

\subsubsection{Enfoque centrado en las victimas y en la humanidad ${ }^{51}$}

Aguilar Cavallo expresa que el derecho penal interno está centrado en el reo, pero el DPI está elaborado en torno a la víctima, por lo cual, frente a los crímenes internacionales, los jueces nacionales deben realizar un análisis y aplicación de las normas de una forma diferente. Esta concepción obedece a "un cambio de la cuestión moral dentro del derecho, el cual fue iniciado por la imprescriptibilidad de los crímenes contra la humanidad, que es la primera piedra de un derecho universal" 52 .

\subsubsection{Principio finalista 53}

La persecución de los crímenes de lesa humanidad tiene un fin preventivo, uno sancionador y uno reparador, frente a los cuales, si opera la prescripción civil, no permitirá que

49 Aguilar Cavallo, Gonzalo, op. cit. (n. 2), p. 182.

50 Guzmán Dalbora, José Luis, Informe de Chile. En: Ambos, Kai, et al. (editores). Jurisprudencia latinoamericana sobre Derecho Penal Internacional, con informes adicionales de España e Italia. Montevideo, Uruguay: Fundación Konrad-Adenauer, 2008, p. 154.

51 Aguilar Cavallo, Gonzalo. op. cit. (n. 2), p. 182.

52 "Un déplacement de la question morale dans le droit, lequel avait été amorcé par l'imprescriptibilité du crime contre l'humanité, première pierre d'un droit universal ", en Cнамве, David. "Réflexions sur la moralisation du droit international" en: Revue de la Recherche Juridique. Marseille, Francia: Presses Universitaires D’Aix-, 2002-1, p. 509.

53 Aguilar Cavallo, Gonzalo. op. cit. (n. 2), p. 182. 
se cumplan a cabalidad los citados fines. Estos obedecen a "la relación del derecho internacional junto a la moral, que parece haber llevado a una legalización necesaria de la misma -tal es la imprescriptibilidad de los crímenes contra la humanidad- una justificación moral del poder, en nombre de un buen derecho" 54 . Roulot señala que en Francia la represión de los crímenes contra la humanidad es entendida como una obligación de ius cogens, que dio origen a la ley de 26 de diciembre de 1964 tendiente a impedir la aplicación de la prescripción frente a estos ilícitos. Sin embargo, el problema que se ha presentado es el principio de la no retroactividad de la ley, pues se trata de juzgar hechos que fueron cometidos con anterioridad a la normativa especial, y que al aplicarla se encuentra con que el transcurso del tiempo hace operante la prescripción común ${ }^{55}$. Zaffaroni plantea "la retroactividad de la imprescriptibilidad de las acciones emergentes de crímenes contra la humanidad, incluso con anterioridad a la vigencia de la norma consuetudinaria de derecho internacional, pues refuerza el carácter criminal del ilícito, cuyos efectos siguen demandando reparaciones" 56 . La norma consuetudinaria, a la cual se refiere, es la Convención sobre la Imprescriptibilidad de los crímenes de guerra y de los crímenes de lesa humanidad, de 1968, a la cual la doctrina y jurisprudencia le reconocen la calidad de ius cogens.

\subsubsection{Principio de la reparación integral ${ }^{57}$}

Este principio es un tema de vital importancia, se traduce en un derecho para el afectado y una obligación para el infractor de los DD.HH., y se posiciona como el medio palpable de la represión de los crímenes contra la humanidad. La reparación integral presenta múltiples funciones, a saber; disuadir, sancionar, ejemplificar, y, sobre todo, restablecer el orden quebrantado cuando sea posible, o de una forma sustitutiva. Zaffaroni nos enseńa que “invocar la simple prescripción civil para negar cualquier derecho de reparación o de restitución en caso de crímenes contra la humanidad cometidos siglos anteriores no es una mera cuestión de neutralización del reclamo, sino un verdadero escándalo jurídico ${ }^{58}$ ".

\subsection{El CASO FRANCÉS FRENTE A LOS CRÍMENES CONTRA LA HUMANIDAD}

Jean-François Roulot expone que la primera vez que se estuvo frente al problema de la no retroactividad de la ley fue en el affaire Touvier, de 30 de junio de 1976, en el cual la Cámara de Acusación distinguió entre los actos prescritos al 26 de diciembre de 1964 y los

\footnotetext{
54 En d'autres termes, la relation du droit international à la morale semble s'être transportée d'une juridicisation nécessaire de la morale -telle l'imprescriptibilité du crime contre l'humanité- vers une justification morale du fait de la puissance au nom du bon droit, en Chambe, David. op. cit. (n. 52), p. 510.

55 Ibid., p. 396.

56 Zaffaroni, Eugenio Raul. op. cit. (n. 58), p. 264.

57 Aguilar Cavallo, Gonzalo. op. cit. (n. 2), p. 183.

58 Zaffaroni, Eugenio Raúl. op. cit. (n. 58), p. 263.
} 
que no lo estaban aún. No obstante, la Corte de Casación francesa no se pronunció sobre el fondo de la discusión pues se enfocó en materias tangenciales a la problemática. A pesar de esto, la actitud de la Corte demostró apegarse al derecho internacional. Un segundo caso fue el affaire Barbie, de 26 de enero de 1984, para la resolución de este caso se contó con la interpretación oficial de los textos internacionales dada por el ministro de Asuntos Exteriores en 1979, quien señaló que "el único principio en materia de prescripción de crímenes contra la humanidad que puede interpretarse, que se infiere, del Estatuto del TMI, es el principio de la imprescriptibilidad”, por tanto, la ley de 1964 no atenta contra la legalidad pues no crea derechos, sino que constata su existencia ${ }^{59}$. Más adelante, se señaló que la imprescriptibilidad se aplica tanto a la acción pública como a la acción civil, pues el art. 10 del CPP dice: "la acción civil prescribe según las reglas del CC. Sin embargo, esta acción no puede ser ejercida ante la jurisdicción represiva después del plazo de prescripción de la acción pública" 60 . De esta forma, "la Corte Criminal de Bordeaux condenó, los días 2 y 3 de abril de 1998, a Maurice Papon no solo a diez años de reclusión por complicidad en crímenes contra la humanidad sino que igualmente a pagar una indemnización a las partes civiles en reparación del perjuicio causado" 61 . Austry señala que en Francia se ha aceptado la imprescriptibilidad de la acción civil derivada de los crímenes contra la humanidad, ello resulta de conjugar el art. 10 del CPP y el Estatuto del TMI de Nuremberg, recogido en el artículo 212-1 del Código Penal. A su vez, se ha sostenido que la responsabilidad del Estado, por el daño causado, se podrá perseguir ante los tribunales ordinarios cuando el ilícito internacional atente contra la libertad individual en el sentido del art. 136 del CPP francés, o en sede administrativa. Sin embargo, no es una opinión pacífica, por lo cual se pueden esgrimir tres objeciones que se oponen a la imprescriptibilidad: la falta personal, oportunidad y la responsabilidad del gobierno actual ${ }^{62}$. Con todo, Austry cita a Claude Lombois, quien justifica la imprescriptibilidad en que "el paso del tiempo, más allá de hacer desaparecer las pruebas, permite, un recuento más avanzado de los registros, una mejor manifestación de la verdad. El escándalo de la inmunidad del crimen no se apaga con el tiempo, todo lo contrario"63.

59 Ibid., pp. 396-398.

60 "La Cour de cassation a alors considéré que l'imprescriptibilité s'appliquait non seulement à l'action publique mais également à l'action civile. Elle a fondée cette solution sur les dispositions de l'article $10 \mathrm{du}$ code de procédure pénale, qui disent: L'action civile se prescrit selon les règles du code civil. Toutefois, cette action ne peut plus être engagée devant la juridiction répressive après le délai de prescription de l'action publique", en Austry, Stéphane. "La réparation du préjudice subi par les orphelins de déportés juifs: aide ou responsabilitée” en: Revue Française de Droit Administratif. París, Francia: Editorial Dalloz, año 17, n 3 mayo-junio, 2001, p. 718.

61 La cour d'assises de Bordeaux a d'ailleurs condamné, les 2 et 3 avril 1998, Maurice Papon non seulement à dix ans de réclusion criminelle pour complicité de crimes contre l'humanité mais également à verser une indemnité aux parties civiles en réparation du préjudice subi, en Austry, Stéphane. op. cit. (n. 60), p. 719.

62 Ibid., pp. 719-720.

63 Le temps passé, loin de faire dépérir les preuves, permet, par le dépouillement plus avancé des archives, une meilleure manifestation de la vérité. Le scandale de l'immunité du crime ne s'émousse pas avec les temps, bien au contraire. Citado por Austry, Stéphane. op. cit. (n. 60), p. 720. 


\section{CONCLUSIONES}

Los crímenes de lesa humanidad, calificación atribuida a las violaciones a los DD.HH. cometidas durante el gobierno militar en Chile son de carácter imprescriptible, siendo excepción a la institución de la prescripción extintiva. Tal característica no es solo privativa del orden penal, sino que también alcanza a la acción civil que surge de tales ilícitos, pues otorgar reparación civil a las víctimas dota de operatividad a los DD.HH. y da respuesta a la obligación que compete al Estado de reparar de forma integral a los afectados.

Sin embargo, la jurisprudencia ha establecido un híbrido respecto a la prescripción de las acciones reparatorias que surgen de los crímenes de lesa humanidad, en cuanto le reconoce la calidad de imprescriptibles a las acciones penales pero niega dicho carácter a la acción indemnizatoria civil, tal situación se ha generado por cambios en la integración de la sala respectiva en la Corte Suprema, pues mientras unos ministros y abogados integrantes aceptan la imprescriptibilidad de ambas acciones, otros la rechazan. 


\section{REFERENCIAS BIBLIOGRÁFICAS}

Aguilar Cavallo, Gonzalo. "Crímenes internacionales y la imprescriptibilidad de la acción penal y civil: referencia al caso chileno", en: Revista Ius et Praxis, año $14 \mathrm{n}^{\circ}$ 2, Talca, Chile: Universidad de Talca, 2008.

Austry, Stéphane. "La réparation du préjudice subi par les orphelins de déportés juifs: aide ou responsabilité?", en: Revue Française de Droit Administratif. París, Francia: Editorial Dalloz, año 17, n 3 mayo-junio, 2001.

Bassiouni, M. Cherif. Introduction au Droit Pénal International. Bruxelles, Belgique: Ed. Bruylant, 2002.

Benadava, Santiago. Derecho Internacional Público -8a edición- Santiago, Chile: LexisNexis, 2004.

Beristain, Antonio. Proceso penal y víctimas: Pasado, presente y futuro. En: Reyna, Miguel (coordinador). Victimologia y Victimodogmática. Una aproximación al estudio de la Victima en el Derecho penal -1a edición- Lima, Perú: ARA Editores E.I.R.L., 2003.

Blanc Altemir, Antonio. La violación de los derechos humanos fundamentales como crimen internacional -1a edición- Barcelona, España: Bosch Casa Editorial S.A., 1990.

Carocca Pérez, Alex. Manual el nuevo sistema procesal penal. -3a edición- Santiago, Chile: LexisNexis, 2005.

Снамве, David. "Réflexions sur la moralisation du droit international", en: Revue de la Recherche Juridique. Marseille, Francia: Presses Universitaires D’Aix-, 2002-1.

Cury Urzúa, Enrique. Derecho Penal. Parte General. -8a edición ampliada- Santiago, Chile: Ediciones Universidad Católica de Chile.

Etcheberry, Alfredo. Derecho Penal. Parte General, Tomo II. -3a edición revisada y actualizada- Santiago, Chile: Editorial Jurídica de Chile. 1998.

Ferrer Lloret, Jaume. Responsabilidad Internacional del Estado y Derechos Humanos -1a edición- Madrid, España: Editorial Tecnos S.A., 1998.

Gamboa Serazzi, Fernando y Fernández Undurraga, Macarena. Tratado de Derecho Internacional Público y Derecho de Integración -2a edición- Santiago, Chile: LexisNexis, 2008.

Garrido Montt, Mario. Derecho Penal. Santiago, Chile: Editorial Jurídica de Chile, 1997.

Guzmán Dalbora, José Luis, Informe de Chile. En: Ambos, Kai, et al. (editores). Jurisprudencia latinoamericana sobre Derecho Penal Internacional, con informes adicionales de España e Italia. Montevideo, Uruguay: Fundación Konrad-Adenauer, 2008.

Horvitz Lennon, María Inés y López Masle, Julián. Derecho procesal penal chileno. Santiago, Chile: Editorial Jurídica de Chile, 2007.

Lirola Delgado, Isabel y Martín Martínez, Magdalena. La Corte Penal Internacional, Justicia versus Impunidad. Barcelona, España: Editorial Ariel S.A., 2001.

Оттеnнof, Reynald. "Les victimes de la criminalité dans un monde globalisé". <En línea> ReAIDP/e-RIAPL, 2008. [citado el 30 de junio de 2010] Disponible en la World Wide Web: <http://www.penal.org/pdf/ Guadalajara-Ottenhof.pdf>

Parma, Carlos, Víctimas. Estado de situación en el proceso penal argentino. En: Reyna, Miguel (coordinador). Victimologia y Victimodogmática. Una aproximación al estudio de la Victima en el Derecho penal. Lima, Perú: ARA Editores E.I.R.L., 2003.

Pérez-León Acevedo, Juan Pablo. "Las violaciones graves de los derechos humanos como crímenes de lesa humanidad”, en Revista del Observatorio Regional sobre Corte Penal Internacional y Derecho Penal Internacional. <En línea> $\mathrm{N}^{\circ}$ 2, mayo 2008, [citado el 25 julio 2010] Disponible en la World Wide Web $<$ http://www.observatoriodpi.org/_data/spda/contenido/20080506125954_.pdf> 
Quel López, Francisco Javier. "Los tribunales Penales Internacionales Ad Hoc". En: Fernández De Casadevante Romani, Carlos (coordinador). Derecho Internacional de los Derechos Humanos. -3a edición- Madrid, España: Editorial Dilex S.L., 2007.

Queralt Jiménez, Joan. Víctimas y garantías: Algunos cabos sueltos a propósito del proyecto alternativo de reparación. En: Reyna, Miguel (coordinador). Victimología y Victimodogmática. Una aproximación al estudio de la Víctima en el Derecho penal. Lima, Perú: ARA Editores E.I.R.L., 2003.

Roulot, Jean-François. Le crime contre l'humanité. París, Francia: Editorial L'Harmattan, 2002.

Troncoso Larronde, Hernán. De las obligaciones. -4a edición- Santiago, Chile: LexisNexis, 2006.

Valencia Villa, Alejandro (compilador y editor general). Compilación de Derecho Penal Internacional, El Estatuto de Roma y otros instrumentos de la Corte Penal Internacional. Bogotá, Colombia: Oficina en Colombia del Alto Comisionado de las Naciones Unidas para los Derechos Humanos, 2003.

Zaffaroni, Eugenio Raúl. En torno de la cuestión penal. Montevideo-Buenos Aires: Editorial IB de F, 2005. 